Haijun WANG

Guoyong DENG

Qinglin LI

Qiang KANG

\title{
RESEARCH ON BISPECTRUM ANALYSIS OF SECONDARY FEATURE FOR VEHICLE EXTERIOR NOISE BASED ON NONNEGATIVE TUCKER3 DECOMPOSITION
}

\author{
BADANIA NAD ANALIZĄ BISPEKTRUM CECH DRUGORZĘDNYCH \\ HAŁASU ZEWNĘTRZNEGO POJAZDÓW \\ W OPARCIU O NIEUJEMNĄ DEKOMPOZYCJĘ TUCKERA3
}

\begin{abstract}
Nowadays, analysis of external vehicle noise has become more and more difficult for NVH (noise vibration and harshness) engineer to find out the fault among the exhaust system when some significant features are masked by the jamming signals, especially in the case of the vibration noise associating to the bodywork. New method is necessary to be explored and applied to decompose a high-order tensor and extract the useful features (also known as secondary features in this paper). Nonnegative Tucker 3 decomposition (NTD) is proposed and applied into secondary feature extraction for its high efficiency of decomposition and well property of physical architecture, which serves as fault diagnosis of exhaust system for an automobile car. Furthermore, updating algorithm conjugating with Newton-Gaussian gradient decent is utilized to solve the problem of overfitting, which occurs abnormally on traditional iterative method of NTD. Extensive experimen results show the bispectrum of secondary features can not only exceedingly interpret the state of vehicle exterior noise, but also be benefit to observe the abnormal frequency of some important features masked before. Meanwhile, the overwhelming performance of NTD algorithm is verified more effective under the same condition, comparing with other traditional methods both at the deviation of successive relative error and the computation time.
\end{abstract}

Keywords: feature extraction, vehicle exterior noise, NTD, updating algorithm.

\begin{abstract}
Obecnie inżynierowie NVH (zajmujący się problematyką hałasu, drgań i uciążliwości akustycznych) napotykają na coraz większe trudności przy analizie hałasu zewnętrznego pojazdów wynikające z faktu, że istotne cechy zwiąane z nieprawidłowościami uktadu wydechowego sa maskowane przez sygnały zaktócające, szczególnie hałas wibracyjny zwiazany z praca nadwozia. Niezbędna jest zatem nowa metoda, która pozwoli rozkładać tensory wysokiego rzędu i wyodrębniać przydatne cechy (zwane w tym artykule także cechami drugorzędnymi). Do ekstrakcji cech drugorzędnych wykorzystano w prezentowanej pracy metodę nieujemnej faktoryzacji tensorów znana także jako nieujemna dekompozycja Tuckera 3 (NTD), która cechuje się wysoka efektywnościa dekompozycji i może być wykorzystywana w diagnostyce uszkodzeń układu wydechowego samochodów. Problem nadmiernego dopasowania, który występuje w tradycyjnej metodzie iteracyjnej NTD rozwiąano przy pomocy algorytmu aktualizacyjnego sprzężonego z gradientem prostym Newtona-Gaussa. Wyniki doświadczeń pokazuja, że bispektrum cech drugorzędnych nie tylko pozwala doskonale interpretować stan hałasu zewnętrznego pojazdu, ale również umożliwia wykrywanie wcześniej maskowanych nieprawidlowych czestotliwości odpowiadajacych niektórym ważnym cechom. Badania potwierdzaja, że algorytmu NTD jest bardziej efektywny, w tych samych warunkach, w porównaniu z innymi tradycyjnymi metodami zarówno $w$ zakresie odchyleń btędu względnego jak i czasu obliczeń.
\end{abstract}

Stowa kluczowe: ekstrakcja cech, hałas zewnętrzny pojazdu, NTD, algorytm aktualizacyjny.

\section{Introduction}

Recently, nonnegative Tucker3 decomposition (NTD), also known as a generalized form of nonnegative tensor factorization (NTF) model, has received hot attention by a considerable amount of people for its overwhelming performance of decomposition efficiency on multi-way dataset decomposition [1]. Both NTD and NTF here can be viewed as high-order extensions of non-negative matrix factorization (NMF) method as referred in some literatures about relationship between NTF/NTD and NMF, all of whose factors are based on an alternating minimization of cost functions incorporating distances or divergences measures with its application in environmental data analysis and can be found in reference therein [2]. NTF with its form of hierarchical alternative least square (ALS) is applied into blind signal separation, of whose alpha and beta divergences methods both are involved in as well [3]. Then much more reseach has been done with NTF itself and gradually evolved to be NTD model.

Mostly, NTD is explored and applied to decompose larger-scale tensors in data analysis. Just one of crucial usages of NTD is of feature extraction from high-order datasets ranging from signals, images, speech, neuroscience, systems biology, chemometrics, or texts [4-10], and also used for designing complex systems as it is the case of wireless communication systems as the publication of the novel paper [11]. However, some useful features usually masked by jamming signals are still a serious problem to judge one state. For example, overfitting appearing in the iterative procedure would generate a large number of harmonic waves as interrupting signal before feature extraction [12], which brings in hard difficulty in detecting the useful features for fault diagnosis and usually occurs in the frequency analysis of vehicle exte- 
rior noise. Thus, how to avoid overfitting and extract the secondary features to interpret the special state in physical property has become an extremely urgent scheduler for NTD [13].

Physical singal existing in the real-world data is non-negative. Incorporating constraints such as sparseness, smoothness or orthogonality on NTD have been the object of significant works for feature extraction during the last years $[14,15]$. Actually, NTD for multi-way data analysis results from the large volume of current data to be analyzed under non-negative constraint on the factors of Tucker 3 model for the secondary features to be estimated as well, when only nonnegative parameters are physically interpretable [16]. The bispectrum feature of vehicle exterior noise is similar to be non-negative in itself. The hybrid noise by exhaust system is not easy to be certained only depending on the frequency existing on the exhaust pipe, since some coupled noise such as conjugating engine noise with resonant noise of transmission shaft always arises in the process of transferring. So using NTD methodology to extract the secondary features is necessary and practicable in fault diagnosis of exhaust system, whose bispectrum directly extracted from the original noise without interference will be a vital way for NVH engineer. Secondary features extracted by NTD are of physical sparseness in data analysis of vehicle exterior noise and to be shown in the later experiments.

Besides, non-negative constraint forced on all the factors of Tucker3 decompositon is able to radically solve the problem of iteration converge in the calculation procedure, or overcome the overfitting in the case of a large-scale tensor decomposition. Meanwhile, NTD may allow to relax the traditional updating form, and to develop a specialized updating algorithm that improves the performance both in terms of accuracy and computational cost, since it just lends itself to the iteration in the form of Newton-Gaussian gradient descent (NGGD). In fact, NGGD can be developed as a way of updating the factors all-atonce as well. This way will be not only used to reduce the complexity of iterative calculation, but be also an available solution to the robustness of NTD and more significant to the matrices and core tensors, which are crucial to the basis images for reconstructing the secondary feature to analyze the vehicle exterior noise of an automobile car.

\section{NTD algorithm}

\subsection{Definition and notation}

Several expressions are necessary to Tucker3 algorithm dealing with real dataset referred to throughout the paper. Meanwhile, some reviews are made for the notation and definitions that will be used as well. To facilitate the distinction between scalars, vectors, matrices, and higher order tensors, the type of a given quantity will be reflected by its representation: scalars are denoted by italic scripts, e.g., $\alpha, \mu$; vectors are written as bold italic latin lower-case letters, e.g., $\boldsymbol{a}, \boldsymbol{b}$; matrices correspond to bold italic latin capital letters, e.g., $\boldsymbol{A}, \boldsymbol{B}$; and tensors are written as bold italic euclid letters, e.g., $\mathcal{X}, \mathcal{Y}$. The Frobenius norm of a tensor $\mathcal{Y}$ is denoted by:

$$
\|\mathcal{Y}\|_{\mathrm{F}}=\sqrt{\langle\mathcal{Y}, \mathcal{Y}\rangle}
$$

where $\|\bullet\|_{F}$ denotes frobenius norm, which can be find in [17].

Definition (Matricization) Matricization, also known as unfolding, is the process of rearranging an $\mathrm{N}$-way dataset as a set of matrices over product. For example, a tensor $\mathcal{Y} \in \mathbf{R}^{I_{1} \times I_{2} \times \cdots \times I_{N}}$, of the partitioning of the set $\left\{I_{n}, n: \in 1,2, \cdots, N\right\}$, is matricized into two ordered subsets $\mathbf{R}_{1}$ and $\mathbf{R}_{2}$, there exists a subset $\left\{I_{n}, n: \in 1,2, \cdots, N\right\}$ of dimen- sion indices with the length $p$ and $N-p$, respectively, the matricization of $N^{\text {th }}$-order tensor can be described as:

$$
\begin{gathered}
\boldsymbol{Y}_{\mathbf{R}_{1} ; \mathbf{R}_{2}}=\sum_{i_{1}=1}^{I_{1}} \cdots \sum_{i_{N}=1}^{I_{N}} \boldsymbol{y}_{i_{1}, \cdots, i_{N}}\left(\begin{array}{c}
\otimes \boldsymbol{e}_{i_{n}}^{(n)} \\
n \in \mathbf{R}_{1}
\end{array}\right)\left(\left(\begin{array}{c}
\otimes \boldsymbol{e}_{i_{n}}^{(n)} \\
\mathrm{n} \in \mathbf{R}_{2}
\end{array}\right)^{T} \in \mathbf{R}^{R_{1} \times R_{2}},\right. \\
\text { s.t. } \\
\qquad R_{1}=\prod_{n=1}^{p} \mathrm{I}_{n}, R_{2}=\prod_{n=N-p}^{N} I_{n} .
\end{gathered}
$$

Where symbol $\otimes$ denotes kronecker product; $\boldsymbol{e}$ is a unit vector;

round bracket ()$^{T}$ denotes that it returns a permutation vector or matrix.

As the multi-way dataset concered in practical application, it must be transited into a tensor. So the third-order tensor is considered herein and involved in the behind. For instance, matricizing a third- order tensor $\mathcal{Y} \in \mathrm{R}^{I_{1} \times I_{2} \times I_{3}}$ along each mode, three matrices can be obtained and expressed as following, respectively called horizontal, lateral, and frontal matrix slices (see reference [18]):

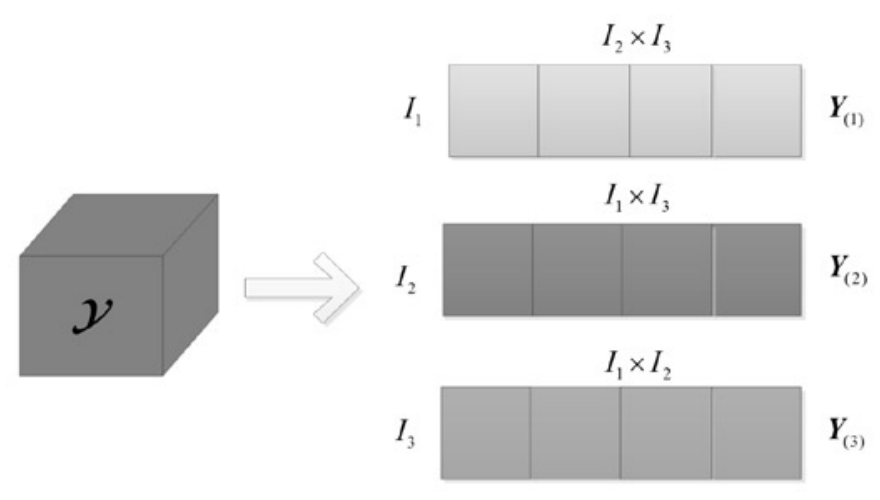

Fig. 1. Model of tensor matricization

$$
\mathbf{Y}_{(n)} \in \mathrm{R}^{\mathrm{I}_{n} \times \mathrm{I}_{s}}, \mathrm{I}_{n}:=\left\{I_{1}, I_{2}, I_{3}\right\}, \mathrm{I}_{s}:=\prod_{s \neq n} I_{s}, \mathrm{n}=\{1,2,3\} .
$$

Furthermore, the three diffirent matrix slices of Eq.(3) can be illustrated as Fig. 1.

\subsection{Tucker model}

Considering an $N$-way tensor $\mathcal{Y} \in \mathbf{R}^{I_{1} \times I_{2} \times \cdots \times I_{N}}$, the generalized approximant of the Tucker model is presented as follows:

$$
\begin{aligned}
\mathcal{Y}= & \widehat{\mathcal{Y}}+E \approx \mathcal{G} \times{ }_{1} A^{(1)} \times{ }_{2} A^{(2)} \cdots \times{ }_{N} A^{(N)}, \text { or } \quad \mathbf{Y}_{(n)}=A^{(n)} \boldsymbol{G}_{(n)}\left(A^{\otimes_{-n}}\right)^{T} .(4) \\
\text { s.t } \quad & A^{\otimes_{-n}}=\boldsymbol{A}^{(N)} \otimes \cdots A^{(n+1)} \otimes A^{(n-1)} \otimes \cdots \otimes A^{(1)} ;\{A\}=\left\{A^{(1)}, \cdots, A^{(N)}\right\} ; \\
& n \leq N ;
\end{aligned}
$$

Where $\widehat{\mathcal{Y}}$ is an approximation of the real-valued $\mathcal{Y}$, symbol $\times_{n}$ denotes the product between mode-n matrix and tensor; $\mathcal{G} \in \mathbf{R}^{J_{1} \times J_{2} \times \cdots \times J_{r}}$ is a core tensor in the Tucker3 model, and the parameters meet $J_{1} \leq I_{1}, J_{2} \leq I_{2}, \cdots, J_{r} \leq I_{n}, r \leq n \leq N$. The Tucker model of Eq. (4) can be rewritten in an element-wise form as: 


$$
\begin{gathered}
\boldsymbol{y}_{i_{1}, \cdots, i_{N}}=\sum_{j_{1}=1}^{J_{1}} \cdots \sum_{j_{r}=1}^{J_{r}} \boldsymbol{g}_{j_{1} \cdots j_{r}} \prod_{n=1}^{N} \boldsymbol{a}_{i_{n}, j_{r}}^{(n)} \\
\text { s.t. } \quad \boldsymbol{a}_{i_{n}, r_{n}}^{(n)} \in \boldsymbol{A}^{(n)}, i_{n} \leq I_{n} .
\end{gathered}
$$

Where $\boldsymbol{g}_{j_{1} \cdots j_{r}}$ and $\boldsymbol{y}_{i_{1}, \cdots, i_{N}}$ are two different elements of the tensors $\mathcal{G}$ and $\mathcal{Y}$, respectively. Physical model of feature extraction consisting of several sub-tenors by NTD method can be represented as Fig. 2.

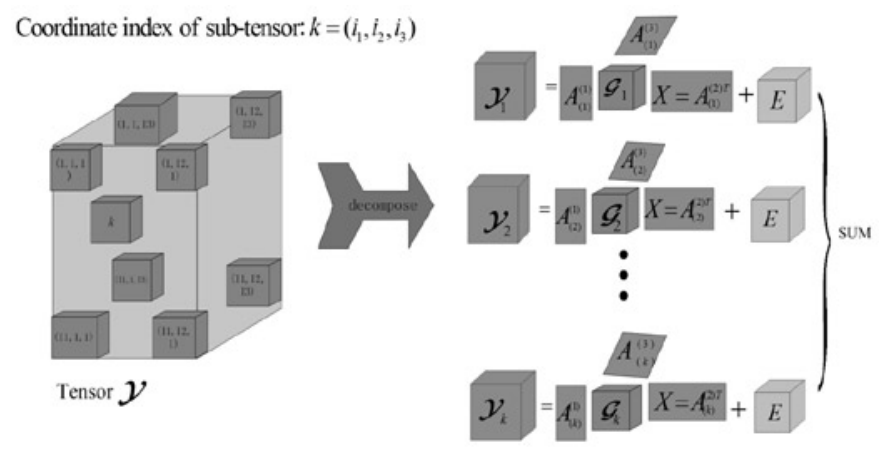

Fig. 2. Feature extraction by Tucker3 model for sub-tensors

Choosing $N^{\text {th }} \leq 3$ as the order of Eq. (4) and Eq.(5) in the real applications. Therefore, the secondary sub-features extracted by Tucker3 algorithm to a third-order dataset are expressed as:

$$
\begin{gathered}
\boldsymbol{y}_{i_{1}, i_{2}, i_{3}}=\sum_{j_{1}=1}^{J_{1}} \sum_{j_{2}=1}^{J_{2}} \sum_{j_{3}=1}^{J_{3}} \boldsymbol{g}_{j_{1} j_{2} j_{3}} \prod_{n=1}^{3} \boldsymbol{a}_{i_{n}, j_{r}}^{(n)}, \\
\text { s.t. } \quad \mathrm{j}_{\mathrm{r}}=\mathrm{j}_{1}, \mathrm{j}_{2}, \mathrm{j}_{3} \leq \min \left\{\mathrm{I}_{\mathrm{n}}\right\}, \mathrm{i}_{\mathrm{n}} \leq \mathrm{I}_{\mathrm{n}}, \mathrm{n} \leq \mathrm{N}
\end{gathered}
$$

Some updating algorithms of Tucker3 decomposition for iterative calculation can be found in [19]. However, traditional updating algorithm usually takes much more computer cost when updating all the factors of NTD algrorithm, especially used to a large-scale tensor. Thus, a novel updating form will be explored for resolving this problem in the following section.

\section{Updating algorithm of iterative calculation}

The method of iteration algorithm via ALS with the way of calculation one-by-one has the advantages of simple mathematical model and lower computer storage requirement, but it has to solve the problems of slow convergence and overfitting in the computation procedure [20]. Herein, the solution of computing the factors all-at-once is applied to overcome these problems.

\subsection{Updating algorithm based on NGGD}

A real-value tensor $\mathcal{Y} \in \mathrm{R}^{\mathfrak{L}}$ is decomposed into $N$ mode matrices $\mathbf{A}^{(n)} \in \mathrm{R}^{I_{n} \times J_{n}}$ and a core tensor $\mathcal{G} \in \mathrm{R}^{J_{1} \times J_{2} \times \cdots \times J_{N}}$. Then all the factors are integrated into a global matrix $\boldsymbol{M}=\left(\boldsymbol{A}^{(1) \mathrm{T}}, \cdots, \boldsymbol{A}^{(N) \mathrm{T}}, \operatorname{vec}(\mathcal{G})\right)$. Operator $\operatorname{vec}(\cdot)$ means a tensor $\mathcal{Y}$ stacks its column into a matrix $\boldsymbol{M}$, which is also known as matricization mentioned above. Besides, the Hessian matrix is often utilized to remedy data overfitting in the calculation procedures.
Therefore, the simultaneously updating algorithm based on the Gauss-Newton gradient descent is expressed in a common formula as:

$$
\mathbf{M}_{+}=\left(\mathbf{M}-\mathbf{H}^{-1} \mathbf{G}\right)_{+},
$$

Where subscript + means adding nonnegative constraint on $\mathbf{M}$. The gradient $\mathbf{G}$ and the approximation Hessian matrix $\mathbf{H}$ are respectively computed by:

$$
\begin{gathered}
\mathbf{G}=\mathbf{K}^{\mathrm{T}}(\widehat{\mathbf{Y}}-\mathbf{Y}), \mathbf{H}=\mathbf{K}^{\mathrm{T}} \mathbf{K}, \\
\text { s.t. } \mathbf{K}=\left[\mathbf{K}_{1}, \mathbf{K}_{2}, \cdots, \mathbf{K}_{N+1}\right], \mathbf{K} \in \mathrm{R}^{\prod I_{n} \times \sum_{n=1}^{N} R_{n} I_{n},}, \\
\mathbf{K}_{n}= \begin{cases}\mathbf{P}_{n}^{\mathrm{T}}\left(\{\mathbf{A}\}_{-n} \mathrm{G}_{(n)}{ }^{\mathrm{T}} \otimes \mathbf{I}_{I_{n}}\right), & n=1,2, \cdots, N, \\
\{\mathbf{A}\}, & n=N+1 .\end{cases}
\end{gathered}
$$

Where $\boldsymbol{Y}=\operatorname{vec}(\mathcal{Y}), \mathcal{Y} \in \mathbf{R}^{\mathfrak{L}} ; \boldsymbol{P}$ is a permutation matrix and $\boldsymbol{K}$ is a Jacobian matrix which can be directly utilized in the iteration Eq. (7); $\{\boldsymbol{A}\}_{-n}$ denotes the Kronecker products of all mode matrices except $\boldsymbol{A}^{(n)}$. However, in the iteration procedure the Hessian matrix $\boldsymbol{H}$ is possible to achieve null point, which can easily cause overfitting and spontaneously enlarge the mean square error [17]. In the sequence, a solution for the iteration Eq. (8) will be presented.

For an Hessian matrix $\boldsymbol{H}$ closing to null point, take an approximate Hessian $\widehat{\boldsymbol{H}}$ instead of $\boldsymbol{H}$, that is, $\widehat{\boldsymbol{H}}=\boldsymbol{H}+u \boldsymbol{I}$, where $0<u \ll 1$. Assuming $f(\cdot)$ is a quadratic function to the real numbers with Hessian of the new form $\widehat{\boldsymbol{H}}=\lambda \boldsymbol{I}$ where $\lambda>0$. Given a point $\boldsymbol{M}^{t+1}=\boldsymbol{M}^{t}-\eta\left(\nabla f\left(\boldsymbol{M}^{t}\right)\right)$, and a decent step $0<\eta<1 / \lambda$ then $f\left(\boldsymbol{M}^{t+1}\right)<f\left(\boldsymbol{M}^{t}\right)$. The process of mathematical proof can also be seen in [19].

The Hessian matrix can alleviate the overfitting happening in the process of the factors calculation. However, the large-scale Hessian matrix demands higher computer cost but lower accuracy [21]. Thus, a more efficient way of computation is required to improve the iterative performance for NTD in the next following.

\subsection{Operator optimization}

From Eq.(8), the simpled function can be deduced as:

$$
\begin{aligned}
\boldsymbol{G} & =\boldsymbol{K}^{\mathrm{T}}(\hat{\boldsymbol{Y}}-\boldsymbol{Y})=\left(\boldsymbol{G}_{(n)-n}\{\boldsymbol{A}\}^{\mathrm{T}}\right) \boldsymbol{P}_{n}^{\mathrm{T}}(\hat{\boldsymbol{Y}}-\boldsymbol{Y}) \\
& =(\widehat{\boldsymbol{Y}}-\boldsymbol{Y})\left({ }_{-n}\{\boldsymbol{A}\}^{\mathrm{T}} \boldsymbol{G}_{(n)}\right) \\
& =\left(\operatorname{vec}(\mathcal{G})\left\{\boldsymbol{A}^{\mathrm{T}} \boldsymbol{A}\right\}^{\otimes_{-n}}-\operatorname{vec}(\mathcal{Y})\{\boldsymbol{A}\}^{\otimes_{-n} \mathrm{~T}}, \boldsymbol{G}_{(n)}\right) \\
& =\operatorname{vec}\left(\left\langle\mathcal{G} \times_{-n}\left\{\boldsymbol{A}^{\mathrm{T}} \boldsymbol{A}\right\}-\mathcal{Y} \times_{-n}\{\boldsymbol{A}\}^{\mathrm{T}}, \mathcal{G}\right\rangle_{-n}\right)
\end{aligned}
$$

Where $\left\langle\bullet_{\bullet}{ }_{-n}\right.$ denotes inner product between two tensors along all the matrices except mode- $n$. the product between core tensor and mode matrices should be demonstrated:

$$
\begin{gathered}
\mathcal{G} \times_{-n}\left\{\boldsymbol{A}^{\mathrm{T}} \boldsymbol{A}\right\}=\mathcal{G} \times{ }_{1} \boldsymbol{A}^{(1) \mathrm{T}} \boldsymbol{A}^{(1)} \times \cdots \times \times_{n-1} \boldsymbol{A}^{(n-1) \mathrm{T}} \boldsymbol{A}^{(n-1)} \times_{n+1} \boldsymbol{A}^{(n+1) \mathrm{T}} \boldsymbol{A}^{(n+1)} \times \cdots \times{ }_{N} \boldsymbol{A}^{(N) \mathrm{T}} \boldsymbol{A}^{(N)} \\
\mathcal{Y} \times_{-n}\{\boldsymbol{A}\}^{\mathrm{T}}=\mathcal{Y} \times{ }_{1} \boldsymbol{A}^{(1) \mathrm{T}} \times \cdots \times \times_{n-1} \boldsymbol{A}^{(n-1) \mathrm{T}} \times_{n+1} \boldsymbol{A}^{(n+1) \mathrm{T}} \times \cdots \times \times_{N} \boldsymbol{A}^{(N) \mathrm{T}} \cdot(10) \\
\text { s.t } \quad \boldsymbol{A}^{(n)} \in \mathrm{R}^{I_{n} \times J_{n}}, \mathcal{G} \in \mathrm{R}^{J_{1} \times \cdots \times J_{n}}, J_{n} \leq I_{n}, n \leq N .
\end{gathered}
$$


The Eq.(10) only needs the length of computation space $I_{n} \times \prod_{k \neq n}^{N} J_{k}$ rather than $\prod_{k \neq n}^{N} I_{k}$ in Eq.(9), which consumes much more computer storage when $I_{n} \gg J_{n}$. Meanwhile, the Eq.(10) is not necessary to reconstruct an approximate tensor $\widehat{\mathcal{Y}}$ any more.

\subsection{Methodology implement}

Conjugating the traditional NTD and the new updating algorithm, the methodology of the NTD algorithm is carried out as following:

Input: $\mathcal{Y} \in \mathrm{R}^{I_{1} \times I_{2} \times I_{3}}$, core tensor $\mathcal{G} \in \mathrm{R}^{J_{1} \times J_{2} \times J_{3}}$, matrices $\boldsymbol{A}^{(1)} \in \mathrm{R}^{I_{1} \times J_{1}}$, $\boldsymbol{A}^{(2)} \in \mathrm{R}^{I_{2} \times J_{2}}, \boldsymbol{A}^{(3)} \in \mathrm{R}^{I_{3} \times J_{3}}, 0<\alpha<1$;

Output: $\quad \boldsymbol{A}^{(1)} \in \mathrm{R}^{I_{1} \times J_{1}}, \boldsymbol{A}^{(2)} \in \mathrm{R}^{I_{2} \times J_{2}}, \boldsymbol{A}^{(3)} \in \mathrm{R}^{I_{3} \times J_{3}}$ and $\mathcal{G} \in \mathrm{R}^{J_{1} \times J_{2} \times J_{3}}, \mathcal{Y}:$.

1 Begin

2 Initializing $A$ and $\mathcal{G}$

3 for $n=1: N$

$4 \quad \boldsymbol{A}^{(n)}=\boldsymbol{Y}_{(n)}(\operatorname{vec}(\operatorname{ttm}(\mathcal{G} \otimes \boldsymbol{A},-n)))_{+} ; \quad / *$ Add nonnegative constraint on $\boldsymbol{A}$

$5 \mathcal{G}=\operatorname{ttm}(\mathcal{Y}, A)$

I*A is Moore-Penrose of $\boldsymbol{A}$

6 if (update $>0) \quad$ Update; end

7 end

$8 \quad \sigma=\|\mathcal{Y}-\widehat{\mathcal{Y}}\|_{F}^{2}$

9 Update

10 for $n=1: N+1$

$11 \boldsymbol{H}=\left(\{\boldsymbol{A}\}_{-n} \mathcal{G}_{(n)}{ }^{\mathrm{T}} \otimes \boldsymbol{I}_{I_{n}}\right)^{\mathrm{T}}\left(\{\boldsymbol{A}\}_{-n} \mathcal{G}_{(n)}{ }^{\mathrm{T}} \otimes \boldsymbol{I}_{I_{n}}\right) ;$

$12 \boldsymbol{M}_{H}=\left(\boldsymbol{A}^{(1) \mathrm{T}}, \cdots, \boldsymbol{A}^{(N) \mathrm{T}}, \operatorname{vec}(\mathcal{G})\right)$;

$13 \boldsymbol{K}_{n}=\{\boldsymbol{A}\}_{-n} \mathcal{G}_{(n)}^{\mathrm{T}} \otimes \boldsymbol{I}_{I_{n}} ;$

14 end

$15 \boldsymbol{K}=\left[\boldsymbol{K}_{1}, \boldsymbol{K}_{2}, \cdots, \boldsymbol{K}_{N+1}\right]$;

$16 \boldsymbol{G}=\boldsymbol{K}^{\mathrm{T}}(\hat{\boldsymbol{Y}}-\boldsymbol{Y})$;

$17 \quad \boldsymbol{M}_{H_{+}}=\left(\boldsymbol{M}-\boldsymbol{H}^{-1} \boldsymbol{G}\right)_{+} ; \quad / * \quad$ Add nonnegative constraint on $\boldsymbol{M}_{H}$

18 if $\left(\right.$ error $\leq 10^{-3}$ or delta $=0$ or iteration $\left.\geq 3000\right)$ stop , end

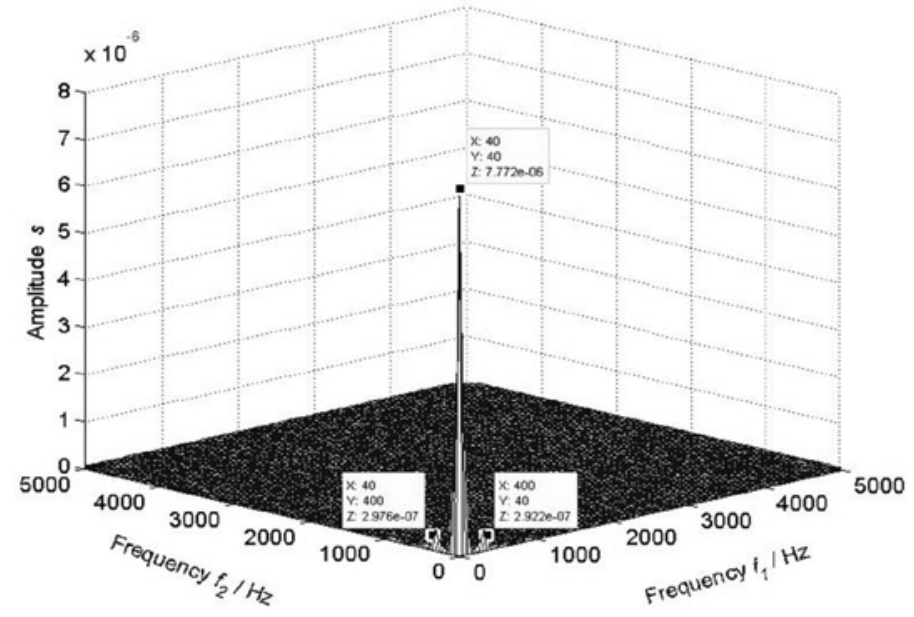

(a) Get rid of thermal shield with damping disk on exhaust pipe

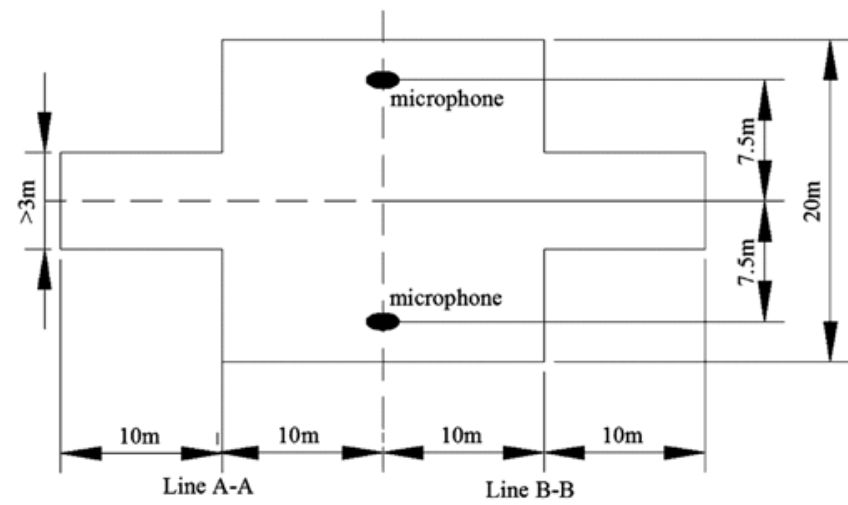

Fig. 3. Layout of the testing ground

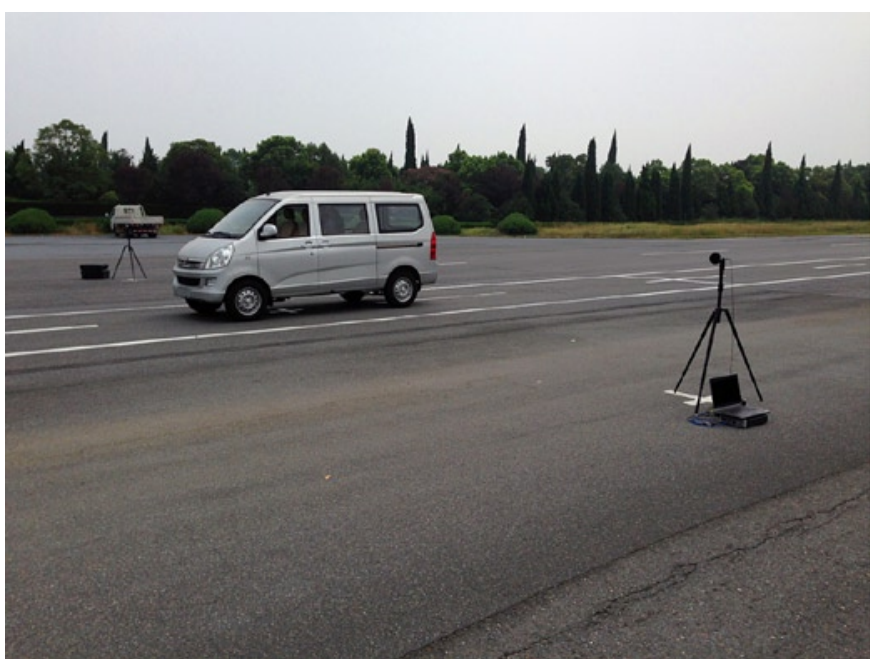

Fig. 4. Test ground with LMS test.lab

\section{Bispectrum analysis of automobile vehicle exterior noise}

The layout of the testing ground can be simply sketched shown as in Fig. 3. Line A-A and Line B-B are the two starting points of acceleration in the case of wide open throttle (WOT) via opposite directions, respectively. The data acquisition equipment of LMS test.lab must be fixed both on the points of the two microphones. Set the sample frequency as $10240 \mathrm{~Hz}$ and the sample time as 10 seconds. The real test ground and the system of LMS test.lab are shown as in Fig.4.

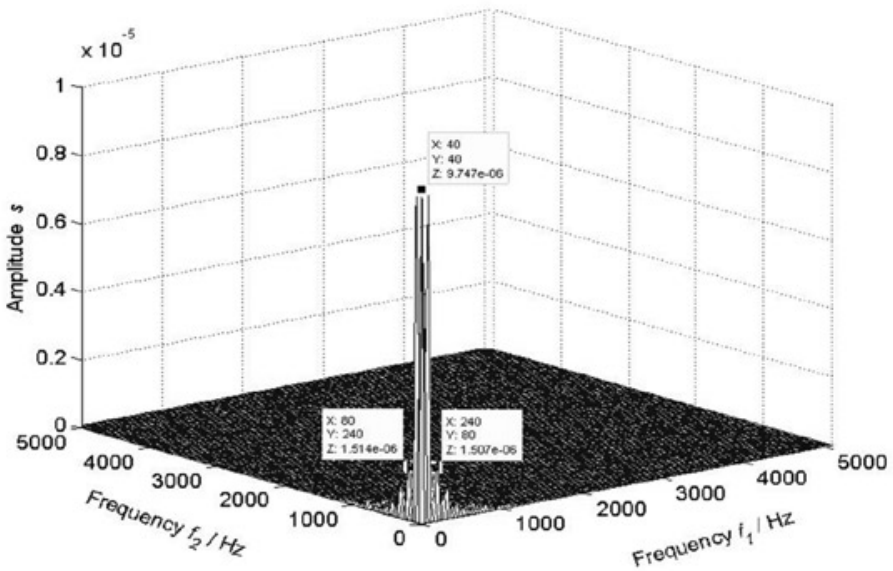

(b) Add new sound package and get rid of thermal shield with damping disk on exhaust pipe

Fig. 5. Bispectrum expression of external vehicle noise 


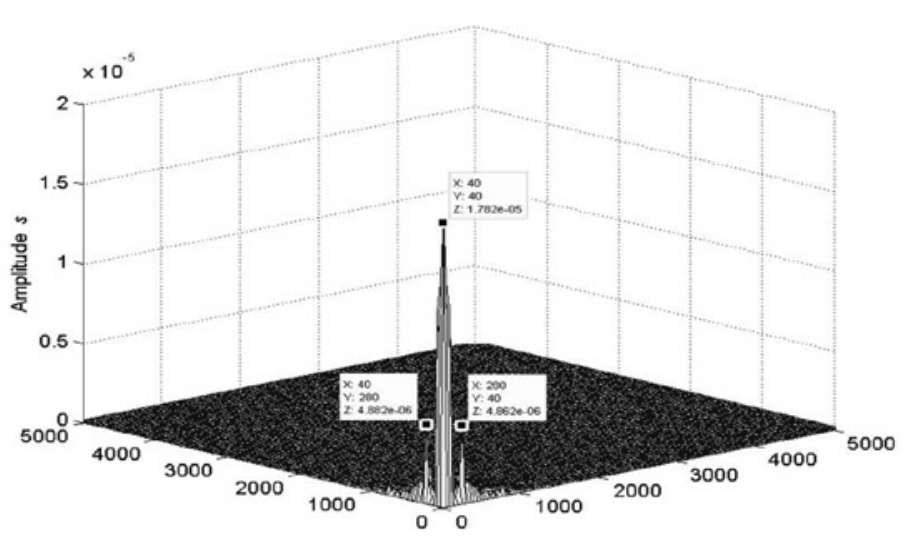

(c) Original state

Fig. 5. Bispectrum expression of vehicle exterior noise

Taking the computation time into account, the length of each test array data is chosen as 65536 or $6.4 \mathrm{~s}$ sample time. Thus the bispecture is consist of the matrix with the size $256 \times 256$. Herein, we choose three different states of vehicle exterior noise as analytical object: (a) get rid of thermal shield with damping disk on exhaust pipe; (b) add new sound package and get rid of thermal shield with damping disk on exhaust pipe; (c) original state with no thermal shield, respectively. The bispectrums of three states are illustrated as Fig. 5, where the figures are plotted with the frequency $f_{1}$ on $\mathrm{x}$-axis, the frequency $f_{2}$ on $\mathrm{y}$-axis and the vibration displacement $\mathrm{S}$ on $\mathrm{z}$-axis(the same below).
The different bispectrums of the vehicle exterior noise are shown as in Fig. 5. It is easy to find that the bispectrums may be confused from the peak values due to interference signals, or some useful signals are masked by other noise, which leads to seriously difficult to judge the state types of the vehicle exterior noise. Fine out the frequency of the noise property belonging to a harmonic pipe is the primary way to NVH engineer. Thus, the methodology of secondary feature extraction is necessary to develop for state recognition once more.

\subsection{Secondary feature extraction}

The experiments are implemented on MATLAB R2012b and partly use the tensor toolbox [22]. White Gaussian noise with the level $0: 0.1: 6.4$ is added on the dataset to reconstruct a new tensor with the size $256 \times 256 \times 64$. Thus, for a third order real tensor, the expression of the secondary feature involved in reference [23] and can be written as:

$$
\mathcal{Y}:=\mathcal{G} \times{ }_{1} A^{(1)} \times{ }_{2} A^{(2)} \times\left(\left(A_{2}^{(2) T} A_{2}^{(2)}\right) *\left(A_{1}^{(1) T} A_{1}^{(1)}\right),\right.
$$

Where $\mathcal{Y}$ : is a set basis images of secondary features. In the initializing phase, the size of the core tensor is set as $(128,128,32)$, which refers to the conclusion about the arguments size of core tensor approximating to one half size of the original tensor referred in [19]. Two basis images of secondary features for each state are extracted from the reconstruction tensor of vehicle exterior noise shown as in Fig. 6.

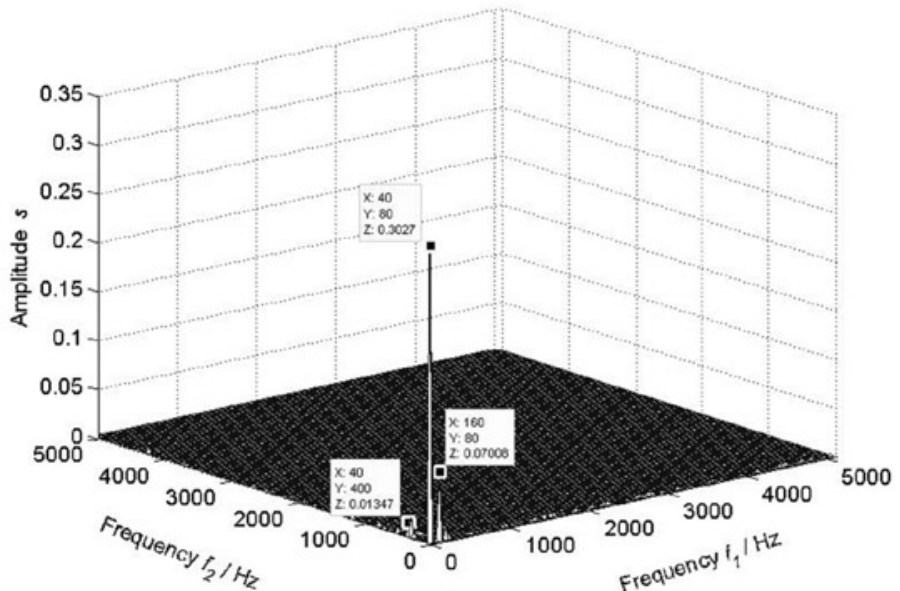

(1)

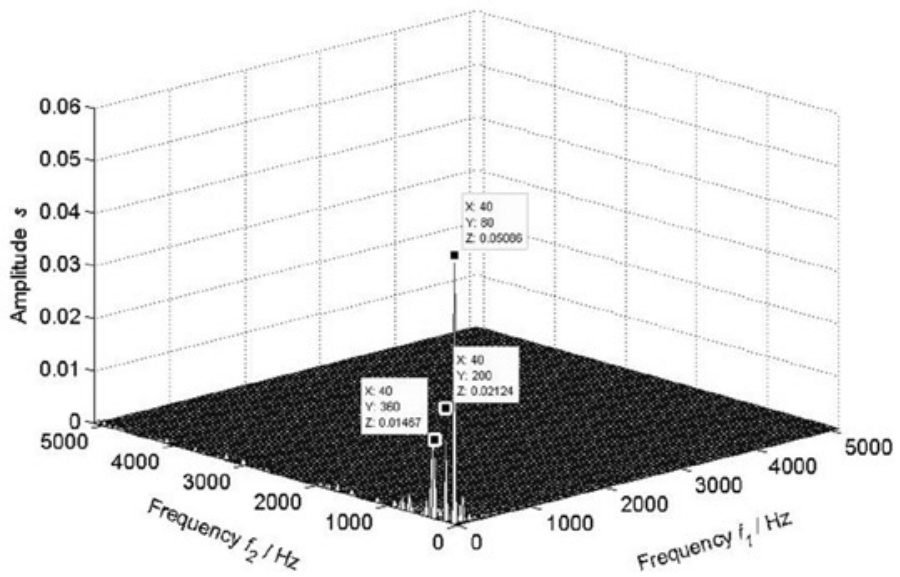

(3)

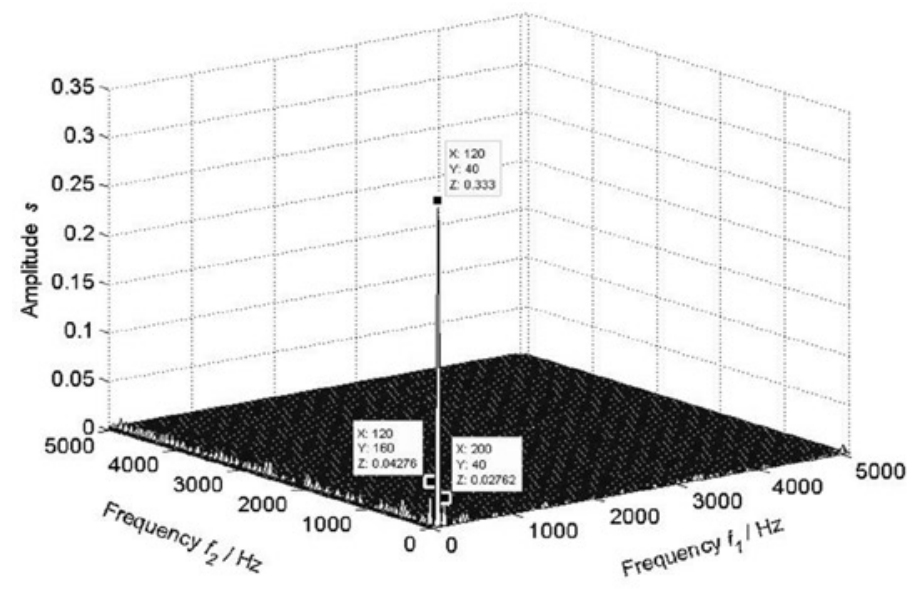

(2)

(a) Get rid of thermal shield with damping disk on exhaust pipe

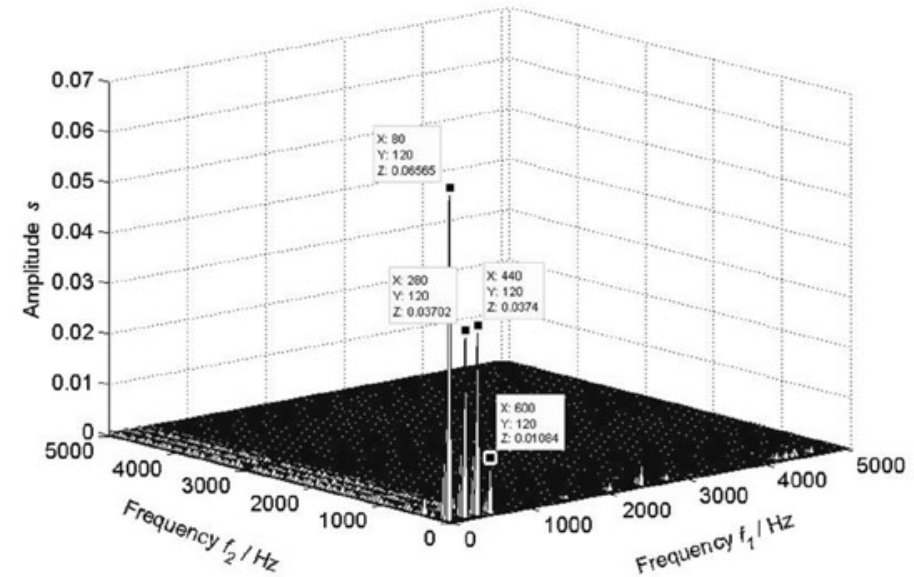

(4)

(b) Add new sound package and get rid of thermal shield with damping disk on exhaust pipe

Fig. 6. Two basis images of secondary features extracted by NTD from vehicle exterior noise (part images) 


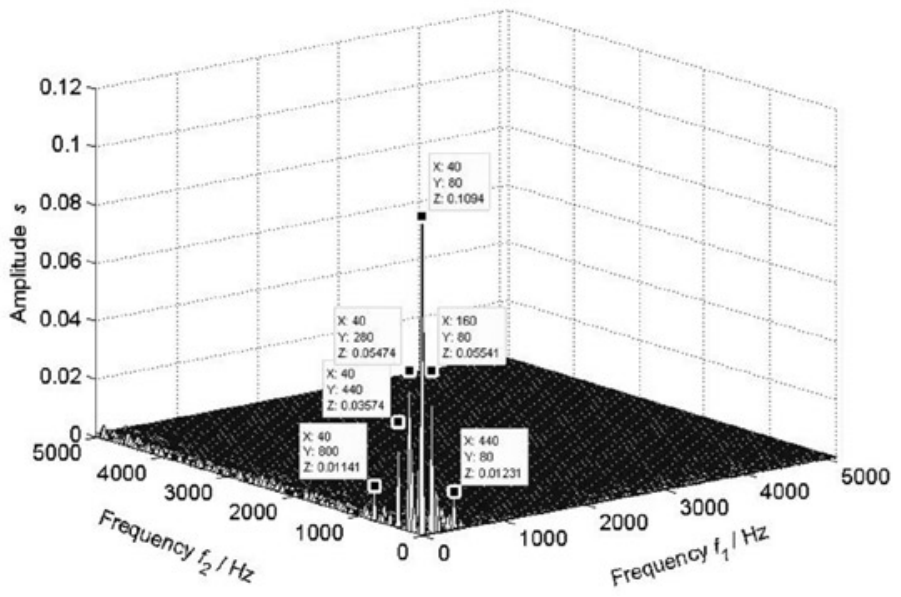

(5)

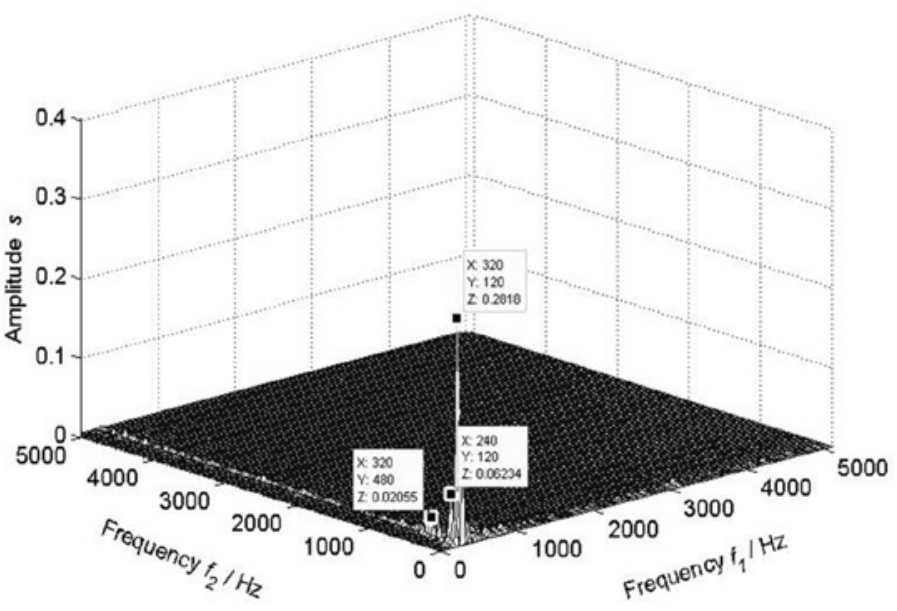

(6)

(c) Original state

Fig. 6. Two basis images of secondary features extracted by NTD from vehicle exterior noise (part images)

From Fig. 6, the primary paired frequency $(40,80)$ (Hertz, the same below) denotes there exists some significant secondary features, which are masked probability before, and against only $40 \mathrm{~Hz}$ alone in Fig.5. Furthermore, along with some other paired frequency multiplication such as $(120,40),(80,120),(220,120)$ arises in the three states that possibly lead to an important argument of harmonic generation and keep the noise rising, which are not revealed absolutely in Fig. 5 as well. Consequently, the analytical way of bispectrum of secondary features extracted by NTD is of significance to expose out the masked signals availably for signal interpretation.

\subsection{Efficiency comparison}

In this section, the NTD method will be used to decompose the same tensor of vehicle exterior noise and compare with other typical algorithms, such as NTF, HNTF with hierarchical ALS and NMF mentioned above, take the pre-existing sample dataset as the object of analytic target. Theoretically, the complexity of each algorithm for a same tensor with the size $n \times n \times n$ is demonstrated as in Table. 1 and to be verified in the following.

Table 1. Complexity for each method

\begin{tabular}{ccccc}
\hline \hline Method & NTD & NTF & HNTF & NMF \\
\hline Complexity & $j_{1} j_{2} j_{3} \log n$ & $j^{3} \log n$ & $j^{3} \log n$ & $n^{3} \log n$
\end{tabular}

Note: $j_{1} \leq n, j_{2} \leq n, j_{3} \leq n ; j_{1}, j_{2}, j_{3} \leq j \leq n$.

Accordding to the Table 1, when under the same condition, the complexity of NTD method is much less comparing with other methods shown as in the columns. If the deviations of successive relative error (DSRE, $\mathrm{dB}$ ) are marked as $\gamma$, that is:

$$
\gamma=-20 \log _{10} \frac{\|\widehat{\mathcal{Y}}-\mathcal{Y}\|_{F}}{\mathcal{Y}_{F}}
$$

Herein, we adopt the DSRE and the computation time as two measure gauges to verify the effect of NTD. Choose $(128,128,32)$ as the rank of core tensor for the different scale tensors. Results of all methods about DSRE $(\gamma / \mathrm{dB})$ and time $(t / \mathrm{s})$ are recorded in Table 2.
Table 2. Computation results of different methods from three dataset

\begin{tabular}{ccccccc}
\hline \hline \multirow{2}{*}{ Methods } & \multicolumn{2}{c}{$256 \times 256 \times 40$} & \multicolumn{2}{c}{$256 \times 256 \times 48$} & \multicolumn{2}{c}{$256 \times 256 \times 64$} \\
& DSRE & Time & DSRE & Time & DSRE & Time \\
\hline NTF & 14.32 & 1633.00 & 23.56 & 1906.64 & 25.10 & 2500.38 \\
HNTF & 21.04 & 1008.60 & 24.99 & 1362.12 & 26.54 & 1878.31 \\
NMF & 15.14 & 3837.60 & 18.76 & 4140.78 & 20.17 & 4785.40 \\
NTD & 28.36 & 987.26 & 28.78 & 1197.17 & 31.03 & 1604.00 \\
\hline \hline
\end{tabular}

(a)

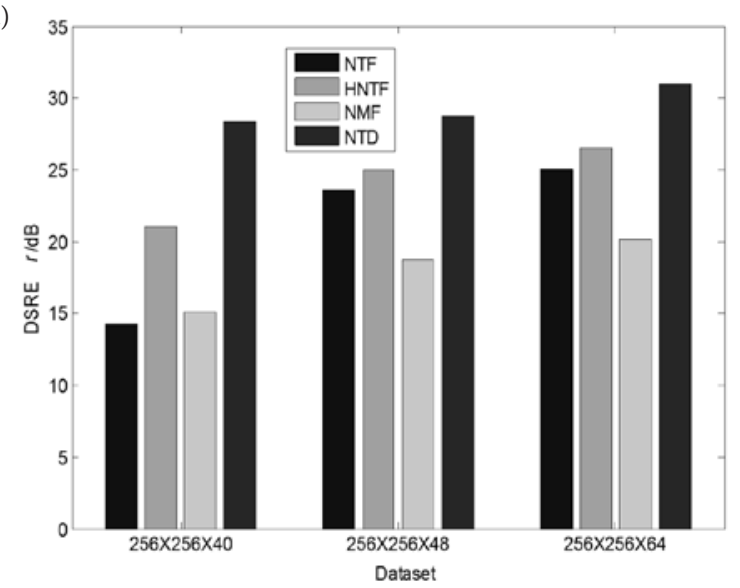

(b)

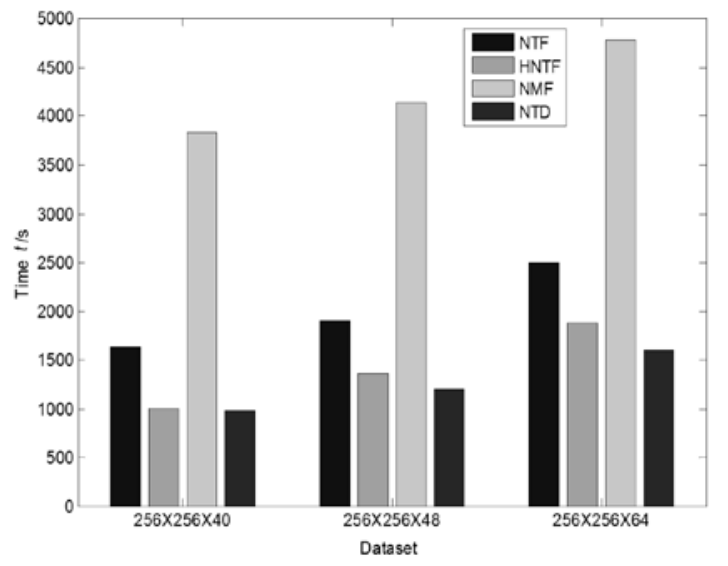

Fig. 7. Bar result comparison of different methods. (a) Computation accuracy, (b) Computation time 
In order to observe the computation results, the bar diagrams are generated from Table.2 shown as in Fig.7.

Combing the bar diagram Fig.7 with the basic data in Table.2, it is easy to find the NTD can reach the highest DSRE with $31.03 \mathrm{~dB}$ but with the least time against other methods under the same condition, shown as in Fig.7 (a). Particularly, the NMF algorithm needs to take the most time with $4785.40 \mathrm{~s}$ to complete the calculation procedure as in Fig.7 (b) but the DSRE with only $20.17 \mathrm{~dB}$, which means lower performance than other methods. The complexity for each algorithm mosltly meets the theoretical expression in Table.1. Thus, the NTD has overwhelming performance in tensor decomposition under the same condition.

\subsection{Results and discussion}

Features extracted by NTD in section 4.1 allow us to know that some secondary features are distinctly exposed out from the masked signals, which maybe generate destructive interference with the real features such as the paired frequency at the $(120,40),(80,120)$ and $(220,120)$ or near the around. Thus, secondary features help us analyzing the natural frequency of the components in the exhaust system. It is an effective way to lower the noise level of exhaust system and improve the NVH (noise, vibration and harshness) in automobile engineering as well. How to offer an approach to revise a component in exhaust system for avoiding the coupling of noise transmission is not involved in NTD, but NTD can provide with more information for the state diagnosis or maintenance. Above all, NTD is a successful tool to NVH engineer and will be a new method in the NVH analysis of an automobile car.

\section{Conclusions}

(1) NTD is proposed to extract the secondary feature for bispectrum analysis of vehicle exterior noise, and the basis images are able to interpret the new features masked before. Method of iteration calculation conjugating with updating algorithm based on NGGD improves the iterative performance of NTD.

(2) The more efficiency and higher accuracy of NTD are verified by different dimensions of the same tensor. Meanwhile, NTD is of success to overcome the problem of overfitting in theory. Related conclusions are also discussed in [24].

(3) Experiments show NTD less complexity comparing other typically methods, and advantages both at the DSRE and computation time.

\section{Acknowledgement}

This project is supported by the fund project of SAIC-GM-Wuling Automobile CO., LTD (Grant No.N310-N12). Thanks to all the engineers of project participants who give strong supports as well.

\section{References}

1. Kopriva I. 3D tensor factorization approach to single-frame model-free blind-image deconvolution, Optics letters 2009; 34(8): 2835-2837, http://dx.doi.org/10.1364/OL. 34.002835

2. Paatero P, Tapper U. Positive matrix factorization - a nonnegative factor model with optimal utilization of error-estimates of data values, Environmetrics 1994; 5(2): 111-126, http://dx.doi.org/10.1002/env.3170050203.

3. Cichocki A, Phan A H , Caiafa C. Flexible HALS algorithms for sparse non-negative matrix/tensor factorization, IEEE Workshop on Machine Learning for Signal Processing 2008: 73 - 78, http://dx.doi.org/10.1109/MLSP.2008.4685458.

4. Kopriva I, Cichocki A. Nonlinear Band Expansion and 3D Nonnegative Tensor Factorization for Blind Decomposition of Magnetic Resonance Image of the Brain. Latent Variable Analysis and Signal Separation 2010, Vigneron V, Zarzoso V, Moreau E, Gribonval R, and Vincent E, Editors, ed: Springer-Verlag Berlin 2010; 6365: 490-497, http://dx.doi.org/ 10.1007/978-3-642-15995-4_61.

5. Kırbız S, Günsel B. A multiresolution non-negative tensor factorization approach for single channel sound source separation. Signal Processing 2014; 105: 56-69, http://dx.doi.org/10.1016/j.sigpro.2014.05.019.

6. Delorme A, Makeig S. EEGLAB: an open source toolbox for analysis of single-trial EEG dynamics including independent component analysis. Journal of Neuroscience Methods 2004; 134: 9-21, http://dx.doi.org/10.1016/j.jneumeth. 2003.10.009.

7. Conesa A, Prats-Montalbán J M, Tarazona S, Nueda MJ, FerreretA. A multiway approach to data integration in systems biology based on Tucker3 and N-PLS. Chemometrics and Intelligent Laboratory Systems 2010; 104: 101-111, http://dx.doi.org/ 10.1016/j.chemolab.2010.06.004.

8. Opriva I, and Jerić I. Blind separation of analytes in nuclear magnetic resonance spectroscopy: Improved model for nonnegative matrix factorization. Chemometrics and Intelligent Laboratory Systems 2014; 137: 47-56, http://dx.doi.org/10.1016/j. chemolab.2014.06.004.

9. Ding H, Ji H. Application of chemometric methods to analyze the distribution and chemical fraction patterns of metals in sediment from a metropolitan river. Environmental Earth Sciences 2010; 61: 641-657, http://dx.doi.org/10.1007/s12665-009-0379-8.

10. Acar E, Yener B. Unsupervised multiway data analysis: A literature survey. IEEE Transactions on Knowledge and Data Engineering 2009; 21: 6-20, http://dx.doi.org/10.1109/TKDE.2008.112.

11. Sidiropoulos N D, Giannakis G B, Bro R. Blind PARAFAC receivers for DS-CDMA systems. IEEE Transactions on Signal Process 2000; 48(3): 810-823, http://dx.doi.org/10.1109/78.824675.

12. Cichocki A, Zdunek R, Phan A H, Amari S I. Alternating Least Squares and Related Algorithms for NMF and SCA Problems, in Nonnegative Matrix and Tensor Factorizations, ed: John Wiley \& Sons, Ltd, 2009: 203-266, http://dx.doi.org/10.1002/ 9780470747278.ch4.

13. Kim H, Park H. Sparse non-negative matrix factorizations via alternating non-negativity constrained least squares for microarray data analysis. Bioinformatics 2007; 23(12): 1494-1402, http://dx.doi.org/10.1093/bioinformatics/btm134.

14. Cichocki A, Zdunek R, Phan A H, Amari S I. Introduction-Problem Statements and Models, in Nonnegative Matrix and Tensor Factorizations. ed: John Wiley \& Sons, 2009:1-75, http://dx.doi.org/http://dx.doi.org/10.1002/ 9780470747278.ch1.

15. Kim Y D, Choi S J. Nonnegative tucker decomposition. IEEE Conference on Computer Vision and Pattern Recognition(CVPR) 2007; 1-8, http://dx.doi.org/ 10.1109/CVPR.2007.383405.

16. Bro R. Multi-way analysis in the food industry: Models, algorithms and applications. PhD thesis, Amsterdam: university of Amsterdam, 1998, http://curis.ku.dk/ws/files/13035961/rasmus_bro.pdf.

17. Chen X R. Introduction to mathematical statistics in Linear model, Beijing : Chinese science press, 2007. (in Chinese)

18. Cichocki A, Zdunek R, Phan A H, Amari S I. Multi-Way Array (Tensor) Factorizations and Decompositions, in: Nonnegative Matrix and Tensor Factorizations. ed: John Wiley \& Sons, 2009; 337-432, http://dx.doi.org/ 10.1002/9780470747278.ch7. 
19. Wang H J, Xu F Y, Zhao J A, Jia M P,Hu J Z, Huang P. Bispectrum Feature Extraction of Gearbox Faults Based on Nonnegative Tucker3 Decomposition with 3D Calculations. Chinese journal of mechanical engineering 2013; 26(6): 1182-1193. http://dx.doi.org/10.3901/ CJME.2013.06.1182.

20. Phan A H, Tichavsky P, Cichocki A, IEEE member. Damped Gauss-Newton algorithm for nonnegative Tucker decomposition. IEEE Conference on Statistical Signal Processing Workshop(SSP) 2011; 665-668, http://dx.doi.org/ 10.1109/SSP.2011. 5967789.

21. Gillis N, Glineur F. A multilevel approach for nonnegative matrix factorization. Journal of Computational and Applied Mathematics 2012; 236(7): 1708-1723, http://dx.doi.org/ 10.1016/j.cam.2011.10.002.

22. Bader B W, Kolda T G. Algorithm 862: MATLAB tensor classes for fast algorithm prototyping. ACM Transactions on Mathematical Software(TOMS) 2006; 32(4): 635-653, http://dx.doi.org/ 10.1145/1186785.1186794.

23. Wang H J, Xu F Y, Wang F. Tensor factorization and clustering for the feature extractionbased on Tucker3 with updating core. Advanced Materials Research, Advanced Design Technology, ADME 2011; 308-310, http://dx.doi.org/ 10.4028/www.scientific.net/AMR.308-310. 2517.

24. Phan A H, Tichavský P, Cichocki A. Low complexity damped Gauss-Newton algorithms for Candecomp/Parafac. Journal on matrix analysis and applications 2013, 34(1): 126-147, http://dx.doi.org/ 10.1137/100808034.

\author{
Haijun WANG \\ Guoyong DENG \\ Qinglin LI \\ Qiang KANG \\ $\mathrm{NVH}$ Institute of vehicle performance integration section \\ SAIC-GM-Wuling Automobile CO., LTD \\ 18 Hexi Road, Liuzhou 545007, Guangxi, P.R. of China \\ E-mails: whjun69@sina.com, Guoyong.Deng@sgmw.com.cn, \\ Qinglin.Li@sgmw.com.cn, Kangqiangok@hotmail.com
}

